\title{
Short Communication: Updated tabular key and improved browser-based interactive key to species of Pratylenchus Filipjev (Nematoda: Pratylenchidae)
}

\author{
ABDUL GAFUR ${ }^{\nu}$ \\ Faculty of Mathematics and Natural Sciences, Universitas Lambung Mangkurat. Jl. Ahmad Yani Km. 36, Banjarbaru 70714, South Kalimantan, \\ Indonesia. Tel./fax.: +62-511-4773112, •email: agafur@ulm.ac.id
}

Manuscript received: 24 June 2020. Revision accepted: 25 July 2020.

\begin{abstract}
Gafur A. 2020. Short Communication: Updated tabular key and improved browser-based interactive key to species of Pratylenchus Filipjev (Nematoda: Pratylenchidae). Biodiversitas 21: 3780-3785. Pratylenchus is the genus of plant-parasitic nematodes that attack many crop plants and cause significant economic losses worldwide. Attempts have been made to control the parasitic nematodes. However, incorrect identification of species has hindered biological studies on the nematodes and has led to improper and inefficient control measures. To facilitate identification of Pratylenchus species, a prototype of a cross-platform, browser-based computer-assisted identification key for species of Pratylenchus has been developed, based on the pre-existing tabular key. This paper described updates and improvements that have been made to enhance the performance of the prototype key. Updates on the tabular key, which the browser-based key was based on, were made primarily to incorporate all-new species that have been subsequently published and new data from further reports of existing species. Illustrations of characters and character states were added to the key to help users decide which character states best correspond to their specimens. Drawings of each species were also given to provide general ideas on how the species look like. The user interface has been revised in which species name(s) relevant to selected character state(s) was listed, instead of highlighted from a lengthy full list.
\end{abstract}

Keywords: Identification, plant parasites, root-lesion nematodes, SAIKS-Plus

\section{INTRODUCTION}

Pratylenchus (root-lesion nematodes) has been well recognized as one of the most important genera of plantparasitic nematodes. Several species of the genus are of worldwide distribution and parasitize a wide variety of plant species, including a range of crops of primary economic importance in all agricultural regions of the world (Castillo and Vovlas 2007). The parasites cause significant economic losses ranking next only to root-knot (Meloidogyne spp.) and cyst (Heterodera spp. and Globodera spp.) nematodes (Jones et al. 2013). All species of this genus are intercellular endoparasitic migratory nematodes that penetrate the root of the host plants, feed and reproduce within the cortical parenchyma of the root, leading to reduced root growth and eventually producing large necroses and cavities in the root cortex (De Luca et al. 2011; Ozbayrak et al. 2019; Jones et al. 2013). The root lesions enhance secondary infection by soil bacteria or fungi, contributing to more agricultural and economic losses (Jones et al. 2013)

Currently, the genus Pratylenchus includes over 80 valid species. Traditionally, identification of the species relies on morphology and morphometrics. Morphological dichotomous (Castillo and Vovlas 2007; Geraert 2013) and polytomous (Castillo and Vovlas 2007) keys have been developed to assist the identification of adult females. However, the species morphological discrimination and delimitation remains challenging and time-consuming, particularly for nonspecialists, because of the small number of available morphological diagnostic characters, the high intraspecific variability of the distinguishing features, the overlapping morphometric measurements, and the many incomplete taxonomic descriptions in the literature (Castillo and Vovlas 2007; Oliveira et al. 2011; Troccoli et al. 2016; Mokrini et al. 2019). It is particularly difficult in the case of mixed species (Mokrini et al. 2016). The difficulty hinders further studies on biology, ecology, and pathogenicity of the parasites, and this may explain why Pratylenchus have been less well studied than some other root endoparasitic nematodes, regardless of their economic importance (Jones et al. 2013). It further put constraints on control strategies and regulatory or quarantine procedures (De Luca et al. 2011; Mokrini et al. 2019) and even on development of molecular-based species identification protocols as mislabelled sequences of Pratylenchus have been detected in public databases (Janssen et al. 2017).

To facilitate identification of species of Pratylenchus, Gafur (2014) prepared a computerized interactive key based on a printed tabular key by Castillo and Vovlas (2007). Written in SAIKS format (@) 2006 Greg Alexander), the prototype (first version) key had the advantages of compatibility, as it could be used with various browsers in different platforms, and of mobility or portability, as it could be accessed with smartphones and tablets, besides laptops and desktop computers. However, the key also inherited the disadvantages of original SAIKS format, primarily in how the species were listed on screen. 
The lengthy list of species names was always displayed, and every time a character state was selected, all species relevant to the selected state would be marked green. It would be easier for users if only relevant species were displayed. Therefore, a revision of the codes of the key was needed. It was also recommended that illustrations be added to make the key more user-friendly.

The original tabular key by Castillo and Vovlas (2007) covered 68 valid species of Pratylenchus. During the preparation of the first version of the present interactive key, it was found that four new species have been described since the publication of the original compendium: $P$. araucensis, $P$. floridensis, $P$. lentis, and $P$. parafloridensis. With the incorporation of the four new species, the number of species covered in the prototype key was 72. However, further literature search suggested that when preparing the original tabular key the authors (Castillo and Vovlas 2007) seemed to be unaware of the publication of three new species; and during the preparation of the prototype interactive key, Gafur (2014) overlooked five other new species that were published between 2006-2013. Furthermore, five additional valid species have been published since 2014. Finally, subsequent records of existing species from different parts of the globe have provided more data on the morphology of the corresponding species. Therefore, an update on the species coverage and character data of the key was urgently needed.

The present paper reported the content update of the tabular key of Pratylenchus by Castillo and Vovlas (2007) and the improvement of the derived interactive key by Gafur (2014).

\section{MATERIALS AND METHODS}

A total of thirteen species of Pratylenchus were added to the tabular key of Castillo and Vovlas (2007) that has been updated by Gafur (2014): P. musii (Geraert 2013; Eisvand et al. 2019); P. gongjuensis (Choi et al. 2006); P. kumamotoensis (Mizukubo et al. 2007; Kim et al. 2016); $P$. ispagoli and P. turmeri (Bairwa et al. 2008); P. speijeri (De Luca et al. 2012), P. oleae (Palomares-Rius et al. 2014), $P$. quasitereoides (Hodda et al. 2014), P. parazeae (Wang et al. 2015; Wu et al. 2019), P. haiduongensis (Nguyen et al. 2017), P. rwandae (Singh et al. 2018), P. horti (Nguyen et al. 2019) and P. capsici (Qing et al. 2019). Two morphotypes of $P$. bolivianus that have been detected (Troccoli et al. 2016) were also incorporated in this update. The new unnamed species found in North Dakota (Yan et al. 2017) was not included because formal species designation has not been made. Code indexes for tabular key of Castillo and Vovlas (2007) for P. araucensis, $P$. capsici, $P$. haiduongensis, $P$. horti, P. oleae, P. parazeae, $P$. rwandae, and $P$. speijeri were taken, with necessary modifications, from the original publications. For other species and morphotypes, the code indexes were determined based on the description in the corresponding publications. Besides including new species, updates on the data matrix were also made by incorporating new information from recent records of existing species. The updated tabular key was then used to update the content of the interactive key to Pratylenchus.

Improvement of the interactive key was also made by adding illustrations of all characters used. Drawings are given as hyperlinks attached to the text of character descriptions. For every species, drawings of general appearance and body parts were also given, excerpted from original or subsequently published descriptions. The illustrations of species were also given as hyperlinks to the text of corresponding species names.

Source code of (https://github.com/kobevds/saiks-plus), derived from SAIKS, was implemented in the present revision. The "index.html" file was revised by changing the paths to javascript and data files. Update on the Pratylenchus data file was made by adding lines for new data.

The updated and improved version of the browserbased key is accessible on https://biodiversitas.ulm.ac.id/nematoda/pratylenchuskey/.

\section{RESULTS AND DISCUSSION}

The tabular key codes for additional species and morphotypes are given in Table 1. Revised codes for existing species are summarized in Table 2. Most existing species showed higher variability in one or more characters with new records of their occurrence in other localities. The increased variability is more prominent in four continuous characters: stylet length (C), vulva position (E), post-vulval uterine sac $(\mathrm{F})$, and pharyngeal overlapping length (I).

With additional thirteen species, the updated tabular key now covers 85 valid species of Pratylenchus. The list covers all species recognized by Castillo and Vovlas (2007) plus three species that might have been overlooked by the authors and subsequent publications of new species. Geraert (2013) recognized 98 species after which seven additional species have been described, making a total of 105 valid species. The difference in number of valid species between the two authorities can be traced back to dissenting opinions regarding the taxonomic status of 19 species. Geraert (2013) did not recognize eleven synonyms and eight species Inquirendae listed by Castillo and Vovlas (2007).

The updated tabular key was then used in updating the interactive key of Gafur (2014). Owing to the default behavior of the original SAIKS format used, in the prototype key all species names are always listed altogether, by default in red background; when a character state is selected, all species names relevant to the selected state will be highlighted green, and the others remain red. This may become inconvenient with an extensive list of species that every time users have to scroll down to check for all relevant species. In the worst case, a user may think that only one species is marked and identification has been made, unaware that deep down the list another species is also marked. This problem becomes more serious with small screen of mobile phones. The SAIKS-Plus code used in the present revised key allows that when a character state 
is selected only relevant species are listed on the screen (Figure 1). With more character states selected, the list becomes shorter and shorter, and eventually only one species left meaning that identification has been made.

In this revision, illustrations of all eleven characters were provided to help inexperienced users determine which character states correspond to their specimens. Drawings from original or subsequent publications of every species were also given to help users gain general ideas on how the species look like and build confidence in their identification. All illustrations were provided as hyperlinks attached to the text of character descriptions or species names. Clicking on the hyperlinks will open a new tab containing the page of corresponding illustrations of the characters or species. Because the key remains accessible when illustrations are displayed, users using computers do not have to switch view between the key and the illustrations. Unfortunately, this advantage is not available to users using mobile phones or tablets.

Conventional printed dichotomous keys to species of Pratylenchus have been used for many years (Castillo and Vovlas 2007; Geraert 2013). However, the keys embrace the disadvantage of dichotomous keys of the painstaking revision as new species, synonymy, or homonymy are found. This is particularly true with species-rich genera such as Pratylenchus.

Table 1. Tabular key codes for additional species and morphotypes of Pratylenchus.

\begin{tabular}{|c|c|c|c|c|c|c|c|c|c|c|c|}
\hline \multirow{2}{*}{ Species } & \multicolumn{11}{|c|}{ Characters } \\
\hline & $\mathbf{A}$ & B & $\mathrm{C}$ & D & $\mathbf{E}$ & $\mathbf{F}$ & $\mathbf{G}$ & $\mathbf{H}$ & I & $\mathbf{J}$ & $\mathbf{K}$ \\
\hline P. bolivianus (amphimictic) & 2 & 2 & 34 & 2 & 3 & 34 & 23 & 12 & 24 & 1 & 1 \\
\hline P. bolivianus (parthenogenetic) & 2 & 1 & 4 & 1 & 3 & 4 & 23 & 1 & 24 & 1 & 2 \\
\hline P. capsici & 2 & 2 & 2 & 2 & 2 & 54 & 32 & 2 & 12 & 1 & 2 \\
\hline P. gongjuensis & 2 & 2 & 23 & 2 & 123 & 6 & 23 & 1 & 2 & 1 & 1 \\
\hline P. haiduongensis & 2 & 1 & 4 & 13 & 1 & 56 & 12 & 14 & 1234 & 1 & 12 \\
\hline P. horti & 1 & 2 & 3 & 3 & 2 & 5 & 2 & 1 & 3 & 1 & 1 \\
\hline P. ispagoli & 2 & 1 & 34 & 3 & 12 & 2 & 3 & 1 & 2 & 1 & 1 \\
\hline P. kumamotoensis & 12 & 2 & 2 & 2 & 123 & 456 & 23 & 12 & 23 & 123 & 1 \\
\hline P. musii & 1 & 1 & 2 & 34 & 23 & 2345 & 23 & 2 & 4 & 3 & 1 \\
\hline P. oleae & 2 & 1 & 23 & 2 & 23 & 345 & 23 & 2 & 12 & 1 & 2 \\
\hline P. parazeae & 2 & 1 & 34 & 3 & 1 & 56 & 23 & 134 & 1234 & 1 & 2 \\
\hline P. quasitereoides & 2 & 1 & 34 & 2 & 23 & 123456 & 2 & 2 & 4 & 1 & 1 \\
\hline P. rwandae & 2 & 1 & 2 & 23 & 2 & 34 & 2 & 1 & 12 & & 1 \\
\hline P. speijeri & 1 & 2 & 34 & 23 & 23 & 456 & 2 & 12 & 123 & 1 & 1 \\
\hline P. turmeri & 2 & 1 & 4 & 4 & 1 & 3 & 3 & 1 & 3 & 1 & 1 \\
\hline
\end{tabular}

Note: Based on Gafur (2014) update to the tabular key of Castillo and Vovlas (2007). Character notation A-K refers to eleven characters described in Castillo and Vovlas (2007).

Table 2. New codes for existing species of Pratylenchus in the tabular key of Pratylenchus.

\begin{tabular}{|c|c|c|}
\hline Species & New codes & References \\
\hline P. brachyurus & E34 I234 & (Flis et al. 2018) \\
\hline P. coffeae & C23 E1234 F23456 I1234 & (T. T. Nguyen 2010) \\
\hline P. crenatus & $\mathrm{C} 23$ & (Kumari 2015) \\
\hline P. curvicauda & E12 J123 & (Begum et al. 2019) \\
\hline P. delattrei & C23 D12 E12 F3456 G23 I123 & (Taheri et al. 2013; Flis et al. 2018) \\
\hline P. fallax & A12 C23 E23 F123 & (Kim and Chun 2014; Saikai et al. 2019) \\
\hline P. goodeyi & B12 C234 E12 & (Zhang et al. 2015; Mgonja et al. 2019) \\
\hline P. hexincisus & F2345 G23 I123 J23 & (Inserra et al. 2007) \\
\hline \multirow{2}{*}{ P. hippeastri } & C23 F56 I234 & (De Luca et al. 2010) \\
\hline & E123 F23456 G23 H13 I1234 & (Wang et al. 2016; Knoetze et al. 2019) \\
\hline P. japonicus & E34 F123 & (Ning et al. 2014) \\
\hline P. kralli & E12 F13 & (Iqbal et al. 2020) \\
\hline P. neglectus & C234 F123 G23 I123 & (Fayazi et al. 2012; Kumari 2012; Yan et al. 2016; Divsalar et al. 2019) \\
\hline P. panamaensis & C34 E23 F23 & (Kim and Chun 2014) \\
\hline P. parazeae & $\mathrm{G} 23$ & (Wu et al. 2019) \\
\hline P. penetrans & E23 & (Kim and Chun 2014) \\
\hline P. pseudocoffeae & $\mathrm{C} 234 \mathrm{E} 23$ & (Kim et al. 2016) \\
\hline P. scribneri & F34 & (Yan et al. 2015) \\
\hline P. tenuis & $\mathrm{C} 23$ & (Girgan 2019) \\
\hline P. thornei & C23 I1234 & (Fayazi et al. 2012) \\
\hline P. vulnus & E23 K12 & (Bakooie et al. 2012; Chihani-Hammas et al. 2018) \\
\hline P. zeae & E12 & (Severino et al. 2010) \\
\hline
\end{tabular}

Note: Based on Gafur (2014) update to the tabular key of Castillo and Vovlas (2007). 


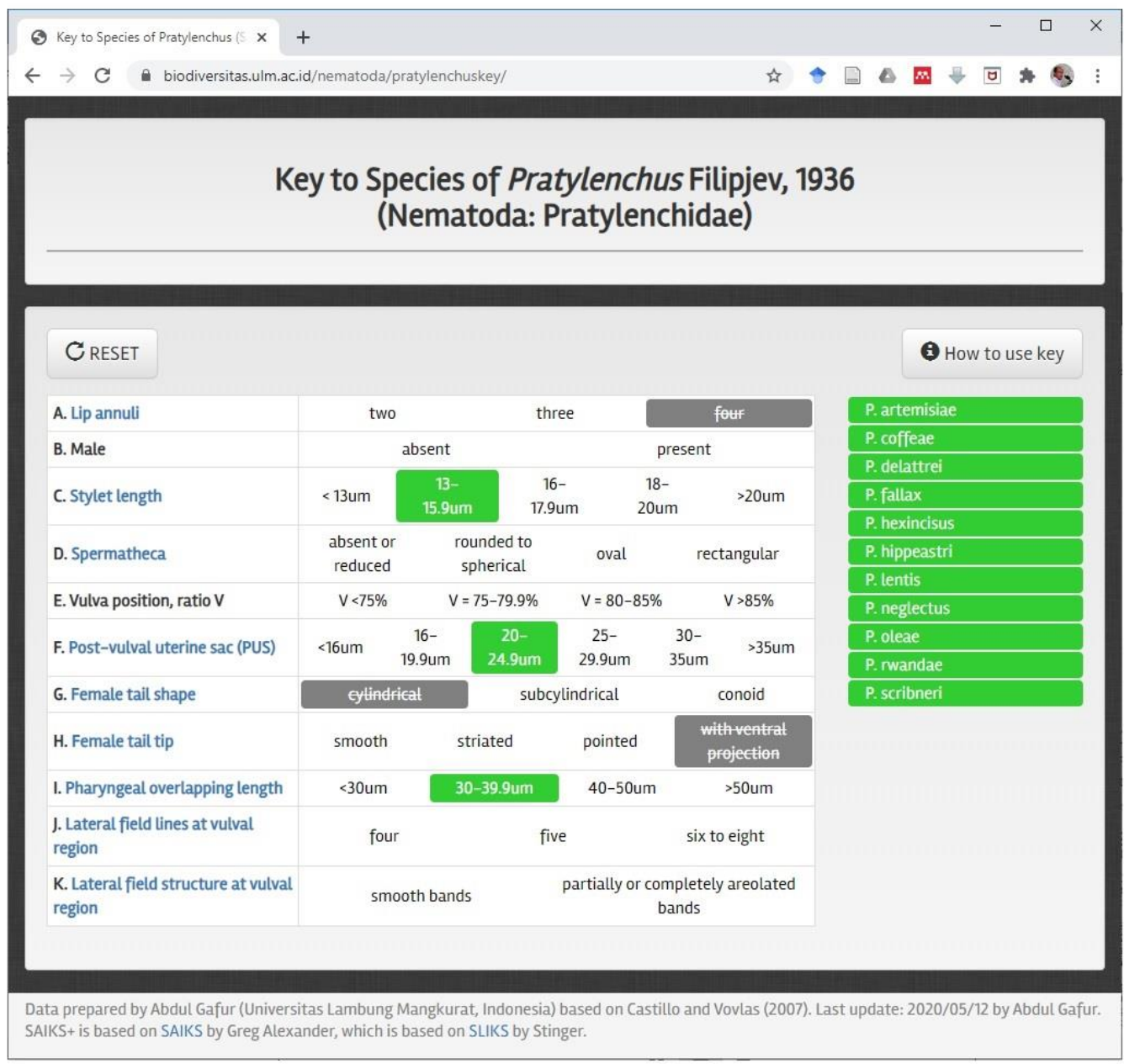

Figure 1. Screenshot of the revised and updated browser-based key to Pratylenchus. Only species relevant to the selected character states are displayed on the species list on the right.

A tabular key to Pratylenchus species has also been developed (Castillo and Vovlas 2007) and has since been consulted by workers in making descriptions of Pratylenchus species. The key inherits the advantage of tabular keys in flexibility of selection of characters and character states, allowing more probability of successful or approximate identification. Despite its usefulness and ease of update, however, it holds the limitation of printed keys in terms of distribution and availability. With species-rich genera such as Pratylenchus, the user-friendliness of the tabular key is compromised.

Based also on the tabular key by Castillo and Vovlas (2007) a web-based key to Pratylenchus has been made and is available online at http://nematodeidentification.mypressonline.com/news/ide ntification-key-for-pratylenchus-spp/. The key (referred to here as the web-based key) is accessible with minimum requirement of a browser application, irrespective of the operating system. Logically, in terms of the core data, system requirements, and availability, the web-based key, and the present (referred to here as the browser-based) key are comparable. However, in the web-based key users have to select relevant character states of all eleven characters before starting the identification. The key starts and displays relevant species only when the execute button is clicked. By contrast, one advantage of the present browserbased key is that users can select any state of any character by clicking those most relevant to their specimens. The browser-based key responds to every single click of selection by displaying all species relevant to the combination of character states selected. Therefore, the present browser-based key can be considered more interactive and user friendly.

There are well-established systems for computerized taxonomic identification, such as Delta-IntKey (deltaintkey.com), Lucid (lucidcentral.com), and Xper (infosyslab.fr), that can easily create valid and feature-rich identification key. However, the systems are not as lightweight as the present browser-based key because they require installation of proprietary software on the end user's machine to produce and to use their keys, and the software are basically not cross-platform and not smartphonefriendly. Lucid recently provides LucidMobile versions of their created keys, but each key has to be downloaded and 
installed on users' phones or tablets. Xper allows users to use its services online to create cross-platform, browserbased single access, and multiaccess keys. Nevertheless, the keys produced by Xper, as well as those created with Delta-Intkey and Lucid, are less responsive and less suitable for small screen compared to the present browserbased key.

On the other hand, the SAIKS and SAIKS-Plus systems, on which the browser-based key is based, do not require any installation of new applications. Keys can be created and edited using any text editor and, more importantly, the created keys can be used with practically any browser, including ones that by default come with the operating systems. The present browser-based key has been tested with popular browsers in both Android and iOS operating systems, as well as Windows and MacOS. Therefore, as an identification tool, the browser-based key is not only less hardware demanding, but it also shows higher compatibility and portability than the more comprehensive systems.

With its responsive and interactive features, the present browser-based key is appropriate for novice users and for identification pieces of training. Owing to its low resource requirement, the key can be used with smartphones and tablets even in the fields and remote places. The major drawback of the browser-based key, and of any internetbased keys, compared to the paper-based counterparts is that it requires internet connection to use. However, with wide availability and improved reliability of internet connection these days, it should not be a serious problem for most users.

\section{ACKNOWLEDGEMENTS}

The author wishes to thank his colleagues and students at the Department of Biology, Faculty of Mathematics and Natural Sciences, Universitas Lambung Mangkurat, Indonesia for testing the key with their computers, tablets, and smartphones.

\section{REFERENCES}

Bairwa IL, Siddiqui AU, and Parihar A. 2008. Two New Species of Pratylenchus Filipjev, 1936 Found Associated with Medicinal Plants in Udaipur District of Rajasthan along with the Report of Pratylenchus zeae Graham, 1951 and P. thornei Sher and Allen, 1953. Pak. J Nematol 26 (1): 13-19.

Bakooie M, Pourjam E, and Javaran MJ. 2012. Investigation on Iranian Pratylenchus vulnus Populations by Morphological and Molecular Marker (RAPD-PCR). J Agric Technol 8 (1): 219-31.

Begum F, Fosu-Nyarko J, Sharma S, Macleod B, Collins S, and Jones MGK. 2019. Serendipitous Identification of Pratylenchus curvicauda from the Grainbelt of Western Australia. J Nematol 51 (1).

Castillo P, and Vovlas N. 2007. Pratylenchus (Nematoda: Pratylenchidae): Diagnosis, Biology, Pathogenicity and Management. Nematology Monographs and Perspectives 6: 1-543.

Chihani-Hammas N, Hajji-Hedfi L, Regaieg H, Larayedh A, Badiss A, Qing Y, and Najet H-R. 2018. First Report of Pratylenchus vulnus Associated with Apple in Tunisia. J Nematol. 50 (4): 579-86. DOI: 10.21307/jofnem-2018-056.
Choi D-R, Lee J-K, Parte B-Y, Han H-R, and Choi Y-E. 2006. A New and One Unrecorded Species of Pratylenchus from Korea (Nematoda: Pratylenchidae). J Asia Pac Entomol 9 (1): 5-9.

Divsalar N, Shokoohi E, Hoseinipour A, and Mashela P. 2019. Molecular and Morphological Variation of the Root-Lesion Nematode Pratylenchus neglectus. Biologia 74 (3): 257-67. DOI: 10.2478/s11756-018-00165-z

Eisvand P, Nejad RF, and Azimi S. 2019. Plant Parasitic Nematodes Fauna in Citrus Orchards in Khuzestan Province, Southwestern Iran. Hell. Plant Prot J 12 (2): 97-107. DOI: 10.2478/hppj-2019-0010

Fayazi F, Farokhi-Nejd R, Ahmadi AR, Memari HR, and Bahmani Z. 2012. Molecular and Morphometric Identification of $P$. thornei and $P$. neglectus in Southwest of Iran. J Plant Pathol Microb 3 (3). DOI: 10.4172/2157-7471.1000123

Flis L, Dobosz R, Rybarczyk-Mydłowska K, Wasilewska-Nascimento B, Kubicz M, and Winiszewska G. 2018. First Report of the Lesion Nematodes: Pratylenchus brachyurus and Pratylenchus delattrei on Tomato (Solanum lycopersicum L.) Plants in Cape Verde. Helminthologia 55 (1): 88-94. DOI: 10.1515/helm-2017-0053

Gafur A. 2014. Kunci Identifikasi Mobil Untuk Spesies Pratylenchus Filipjev, 1936 (Nematoda: Pratylenchidae). In: Wibowo A (ed) Prosiding Seminar Nasional Pengendalian Penyakit pada Tanaman Pertanian Ramah Lingkungan; Perhimpunan Fitopatologi Indonesia Komda Joglosemar dan Universitas Gadjah Mada, Yogyakarta, 20 September 2014. [Indonesian].

Geraert E. 2013. The Pratylenchidae of the World: Identification of the Family Pratylenchidae (Nematoda: Tylenchida). Academia Press, Gent.

Girgan C. 2019. Nematode Fauna in the Telperion Nature Reserve. NorthWest University.

Hodda M, Collins SJ, Vanstone VA, Hartley D, Wanjura W, and Kehoe M. 2014. Pratylenchus quasitereoides n. sp. from Cereals in Western $\begin{array}{lllll}\text { Australia. Zootaxa } 3866 & \text { (2): } 277-88 . & \text { DOI: }\end{array}$ http://dx.doi.org/10.11646/zootaxa.3866.2

Inserra R, Troccoli A, Gozel U, Bernard E, Dunn D, and Duncan L. 2007. Pratylenchus hippeastri n. Sp.(Nematoda: Pratylenchidae) from Amaryllis in Florida with Notes on P. Scribneri and P. Hexincisus. Nematology 9 (1): 25-42.

Iqbal E, Mehmood N, Kazi N, and Fayyaz S. 2020. Description of Paratylenchus manilkarii n. Sp., P. sindhicus $\mathrm{n}$. Sp., and Observation of Pratylenchus Kralli Ryss, 1982 from Chikoo (Manilkara Zapota L. van Royen) Orchards of Balochistan and Sindh, Pakistan. Pak. J. Zool. 52 (2): 693. DOI: https://dx.doi.org/10.17582.

Janssen T, Karssen G, Couvreur M, Waeyenberge L, and Bert W. 2017. The Pitfalls of Molecular Species Identification: A Case Study within the Genus Pratylenchus (Nematoda: Pratylenchidae). Nematology 19 (10): 1179-99.

Jones JT, Haegeman A, Danchin EGJ, Gaur HS, Helder J, Jones MGK, Kikuchi T, Manzanilla-López R, Palomares-Rius JE, and Wesemael WML. 2013. Top 10 Plant-parasitic Nematodes in Molecular Plant Pathology. Mol. Plant Pathol. 14 (9): 946-61. DOI: 10.1111/mpp.12057

Kim D, and Chun J-Y. 2014. Identification of Root-Lesion Nematode (Pratylenchidae: Pratylenchus) Intercepted on Imported Plants. Korean J. Appl. Entomol. 53 (1): 51-57. DOI: 10.5656/KSAE.2013.10.1.083

Kim D, Chun J-Y, and Lee K-Y. 2016. Morphometric and Molecular Characterization of Populations of Pratylenchus kumamotoensis and P. pseudocoffeae (Nematoda, Pratylenchidae) Newly Recorded in Korea. ZooKeys, no. 600: 1. DOI: 10.3897/zookeys.600.8508

Knoetze R, Berg E van den, Girgan C, and Walt L van der. 2019. First Report of the Root Lesion Nematode, Pratylenchus hippeastri, on Apple in South Africa. J. Plant Dis Prot 126 (6): 607-9. DOI: 10.1007/s41348-019-00259-z

Kumari S. 2012. Pratylenchus neglectus (Nematoda: Pratylenchidae) under the Rhizosphere of Brassica napus. Helminthologia 49 (2): $92-$ 95. DOI: 10.2478/s11687-012-0019-9

Kumari S. 2015. Characterization of Pratylenchus crenatus and $P$. neglectus (Nematoda: Pratylenchidae) Associated with Wheat Crop. Helminthologia 52 (3): 280-86. DOI: 10.1515/helmin-2015-0043

Luca F De, Reyes A, Troccoli A, and Castillo P. 2011. Molecular Variability and Phylogenetic Relationships among Different Species and Populations of Pratylenchus (Nematoda: Pratylenchidae) as Inferred from the Analysis of the ITS RDNA. Eur. J. Plant Pathol 130 (3): 415-26. 
Luca F De, Troccoli A, Duncan LW, Subbotin SA, Waeyenberge L, Coyne DL, Brentu FC, and Inserra RN. 2012. Pratylenchus speijeri N. Sp. (Nematoda: Pratylenchidae), a New Root-Lesion Nematode Pest of Plantain in West Africa. Nematology 14 (8): 987-1004. DOI: $10.1163 / 156854112$ X638424

Luca F De, Troccoli A, Duncan LW, Subbotin SA, Waeyenberge L, Moens M, and Nserra RN. 2010. Characterisation of a Population of Pratylenchus hippeastri from Bromeliads and Description of Two Related New Species, P. Floridensis n. sp. and P. Parafloridensis $\mathrm{n}$. Sp. from Grasses in Florida. Nematology 12 (6): 847-68. DOI: 10.1163/138855410X495809

Mgonja D, Temu G, Mziray M, Kashando B, Mwenisongole A, Masunga M, Lyantagaye S, and Luambano N. 2019. Morphological and Molecular Identification of Pratylenchus goodeyi Associated with Banana in Tanzania. Tanzania J. Sci. 45 (2): 265-78.

Mizukubo T, Sugimura K, and Uesugi K. 2007. A New Species of the Genus Pratylenchus from Chrysanthemum in Kyushu, Western Japan (Nematoda: Pratylenchidae). Japanese J. Nematol. 37 (2): 63-74.

Mokrini F, Viaene N, Waeyenberge L, Dababat AA, and Moens M. 2019 Root-Lesion Nematodes in Cereal Fields: Importance, Distribution, Identification, and Management Strategies. J. Plant Dis. Prot. 126 (1): $1-11$.

Mokrini F, Waeyenberge L, Viaene N, Andaloussi FA, and Moens M. 2016. Diversity of Root-Lesion Nematodes (Pratylenchus Spp.) Associated with Wheat (Triticum Aestivum and T. Durum) in Morocco. Nematology 18 (7): 781-801.

Nguyen HT, Trinh QP, Couvreur M, Singh PR, Decraemer W, and Bert W. 2019. Molecular and Morphological Characterisation of a New Root-Lesion Nematode, Pratylenchus horti N. Sp.(Tylenchomorpha: Pratylenchidae), from Ghent University Botanical Garden. Nematology 21 (7): 739-52. DOI: 10.1163/15685411-00003249

Nguyen TD, Le TML, Nguyen HT, Nguyen TAD, Liebanas G, and Trinh QP. 2017. Morphological and Molecular Characteristics of Pratylenchus haiduongensis Sp. N., a New Species of Root-Lesion Nematodes Associated with Carrot in Vietnam. J. Nematol. 49 (3): 276.

Nguyen TT. 2010. A Comparative Polyphasic Study of 10 Pratylenchus Coffeae Populations from Vietnam. Doctoraatsproefschrift. Katholieke Universiteit Leuven.

Ning W, Jianfeng G, Xuan W, and Hongmei L. 2014. Identification of Pratylenchus japonicus Intercepted in Acer palmatum from Japan. J. Nanjing Agric. Univ. Nongye Daxue Xuebao/Nanjuing Nongye Daxue Xuebao 37 (4).

Oliveira CMG de, Monteiro AR, and Blok VC. 2011. Morphological and Molecular Diagnostics for Plant-Parasitic Nematodes: Working Together to Get the Identification Done. Trop Plant Pathol 36 (2): 65 73. DOI: $10.1590 / \mathrm{S} 1982-56762011000200001$

Ozbayrak M, Todd T, Harris T, and Higgins R. 2019. A COI DNA Barcoding Survey of Pratylenchus Species in the Great Plains Region of North America J Nematol 51. DOI: 10.21307/jofnem-2019-081

Palomares-Rius JE, Guesmi I, Horrigue-Raouani N, CantalapiedraNavarrete C, Liébanas G, and Castillo P. 2014. Morphological and Molecular Characterisation of Pratylenchus oleae N. Sp. (Nematoda: Pratylenchidae) Parasitizing Wild and Cultivated Olives in Spain and Tunisia. Eur J Plant Pathol 140 (1): 53-67. DOI: 10.1007/s10658-014$0443-4$
Qing X, Bert W, Gamliel A, Bucki P, Duvrinin S, Alon T, and Braun Miyara S. 2019. Phylogeography and Molecular Species Delimitation of Pratylenchus capsici N. Sp., a New Root-Lesion Nematode in Israel on Pepper (Capsicum Annuum). Phytopathology 109 (5): 847 58.DOI: https://doi.org/10.1094/PHYTO-09-18-0324-R

Saikai K, Handoo ZA, and MacGuidwin AE. 2019. First Report of the Root-Lesion Nematode, Pratylenchus fallax, on Soybean in Wisconsin, USA. Plant Dis.103 (8): 2141. DOI: 10.1094/PDIS-02-190288-PDN

Severino JJ, Dias-Arieira CR, and Tessmann DJ. 2010. Nematodes Associated with Sugarcane (Saccharum Spp.) in Sandy Soils in Parana, Brazil. Nematropica 40 (1): 111-119.

Singh PR, Nyiragatare A, Janssen T, Couvreur M, Decraemer W, and Bert W. 2018. Morphological and Molecular Characterisation of Pratylenchus rwandae N. Sp. (Tylenchida: Pratylenchidae) Associated with Maize in Rwanda. Nematology 20 (8): 781-94. DOI: https://doi.org/10.1163/15685411-00003175

Taheri ZM, Maafi ZT, Subbotin SA, Pourjam E, and Eskandari A. 2013. Molecular and Phylogenetic Studies on Pratylenchidae from Iran with Additional Data on Pratylenchus delattrei, Pratylenchoides alkani, and Two Unknown Species of Hirschmanniella and Pratylenchus. Nematology 15 (6): 633-51. DOI: 10.1163/15685411-00002707.

Troccoli A, Subbotin SA, Chitambar JJ, Janssen T, Waeyenberge L, Stanley JD, Duncan LW, Agudelo P, Uribe GEM, and Franco J. 2016. Characterisation of Amphimictic and Parthenogenetic Populations of Pratylenchus bolivianus Corbett, 1983 (Nematoda: Pratylenchidae) and Their Phylogenetic Relationships with Closely Related Species. Nematology 18 (6): 651-78. DOI: 10.1163/15685411-00002981

Wang H, Zhuo K, Ye W, and Liao J. 2015. Morphological and Molecular Charaterisation of Pratylenchus parazeae N. Sp. (Nematoda: Pratylenchidae) Parasitizing Sugarcane in China. Eur J Plant Pathol 143 (1): 173-91. DOI: 10.1007/s10658-015-0674-z.

Wang H, Zhuo K, and Liao J. 2016. Morphological and Molecular Characterization of Pratylenchus hippeastri, a New Record of RootLesion Nematode Associated with Apple in China. Pak. J. Zool. 48 (3).

Wu HY, Li TJ, Zhou XB, Liu LL, and Gu JF. 2019. First Report of RootLesion Nematode, Pratylenchus parazeae on Maize (Zea Mays) in China. Plant Dis. PDIS-07. DOI: 10.1094/PDIS-07-19-1536-PDN

Yan GP, Plaisance A, Huang D, Chowdhury IA, and Handoo ZA. 2017. First Report of the New Root-Lesion Nematode Pratylenchus Sp. on Soybean in North Dakota. Plant Dis. 101 (8): 1554.

Yan GP, Plaisance A, Huang D, Gudmestad NC, and Handoo ZA. 2015. First Report of the Root-Lesion Nematode Pratylenchus scribneri Infecting Potato in North Dakota. Plant Dis. 100 (5): 1023. DOI: 10.1094/PDIS-10-15-1227-PDN

Yan GP, Plaisance A, Huang D, Liu Z, Chapara V, and Handoo ZA. 2016. First Report of the Root-Lesion Nematode Pratylenchus neglectus on Wheat (Triticum aestivum) in North Dakota. Plant Dis 100 (8): 1794. DOI: 10.1094/PDIS-02-16-0260-PDN

Zhang F, Yan S, Zhou Y, Guo G, Guo S, Jin Z, Zeng H, Peng D, Ruan L, and Sun M. 2015. First Report of Pratylenchus goodeyi on Banana in Hainan Province, China. Plant Dis. 99 (5): 731. DOI: https://doi.org/10.1094/PDIS-08-14-0874-PDN 